\title{
Weight-loss maintenance in overweight individuals one to five years following successful completion of a commercial weight loss program
}

\author{
MR Lowe ${ }^{1}$, K Miller-Kovach ${ }^{2}$ and S Phelan ${ }^{1}$ \\ ${ }^{1}$ Department of Clinical and Health Psychology, MCP Hahnemann University, Philadelphia, Pennsylvania, USA; and ${ }^{2}$ Weight \\ Watchers International, Woodbury, New York, USA
}

OBJECTIVE: To determine weight loss maintenance among participants in a commercial weight loss program (Weight Watchers) who had reached their goal weights $1-5$ y previously.

DESIGN: A national sample $(n=1002)$ was surveyed by phone to obtain demographic and weight-related information. An oversample $(n=258)$ was recruited and weighed in person to develop a correction factor for self-reported weights in the national sample.

RESULTS: Based on corrected weights, weight regain from 1 to 5 y following weight loss ranged between 31.5 and $76.5 \%$. At $5 \mathrm{y}, 19.4 \%$ were within $5 \mathrm{lb}$ of goal weight, $42.6 \%$ maintained a loss of $5 \%$ or more, $18.8 \%$ maintained a loss of $10 \%$ or more, and $70.3 \%$ were below initial weight.

CONCLUSIONS: These results are not directly comparable to those obtained in clinical settings because of differences in the populations studied. Nonetheless, they suggest that the long-term prognosis for weight maintenance among individuals who reach goal weight in at least one commercial program is better than that suggested by existing research.

Keywords: obesity; obesity treatment; weight loss; weight maintenance; dieting

\section{Introduction}

The past $20 \mathrm{y}$ has seen the development of both pharmacological and nonpharmacological weight loss interventions that produce medically significant weight losses of approximately $10 \%$ of initial body weight. ${ }^{1,2}$ However, regardless of the method used to produce weight loss, weight regain inevitably begins once treatment ends. In comprehensive programs combining dietary and lifestyle interventions, onethird to two-thirds of lost weight is regained within $1 \mathrm{y}^{3}$ and virtually all lost weight is regained within $5 \mathrm{y}^{2}$ As Wadden and Sawrer' ${ }^{2}$ recently noted, 'maintaining weight loss remains the single greatest challenge for significantly obese patients and their practitioners'.

The disappointing long-term results of weight loss treatments have been extensively publicized and have contributed to widespread anti-dieting sentiment. ${ }^{4}$ However, nearly all data on weight regain following intentional weight loss have been based on research studies conducted in university or hospital settings. The number of overweight individuals who receive weight-loss treatment in such settings represents a small fraction of the number of overweight people who diet to lose weight in the general population. ${ }^{5}$ Overweight people who seek treatment in university or hospital-based programs exhibit more psychopathology and binge eating than overweight individuals not seeking treatment. ${ }^{6}$ Also, obese individuals treated in clinical settings are more overweight than those treated in commercial programs, and body mass is correlated with both binge eating severity and depression. ${ }^{5}$ Thus there is reason to believe that the nearly exclusive use of clinical populations in studies of the long-term effectiveness of weight-loss treatments may be producing overly pessimistic conclusions.

There is growing recognition of the need to evaluate the outcomes of all forms of weight control practices. In 
particular, since many more overweight individuals seek weight loss treatment in commercial than in clinical programs, collection of data on the long-term effectiveness of commercial programs is particularly important. As noted by The Committee to Develop Criteria for Evaluating the Outcomes of Approaches to Prevent and Treat Obesity, ${ }^{7}$ 'given the billions of dollars consumers currently spend on weightloss programs, we believe that these programs require special attention and evaluation' ( $\mathrm{p}$ 603). Yet, as Hensrud et $a l^{8}$ noted, 'data from commercial programs are conspicuously lacking' ( $p$ 692). The purpose of the present investigation is to assess the maintenance of weight losses among participants in a well-known commercial weight loss program who had reached their goal weights while in the program. Weight loss maintenance was examined for individuals who had reached goal weight between 1 and $5 \mathrm{y}$ previously. Furthermore, data were collected on a large, nationally representative sample, enhancing the generalizability of the results.

There are two vantage points from which to evaluate the outcome of a weight-loss program. The traditional vantage point involves the maintenance of lost weight, as measured by the percentage of individuals who maintained their original weight loss or the percentage of initial weight loss that was subsequently regained. However, accumulating evidence indicates that relatively small, sustained weight losses have medically significant health benefits. ${ }^{9,10}$ The Institute of Medicine has recommended that weight management programs be evaluated on their success in achieving long-term weight loss, which they define as a weight loss of at least $5 \%$ that is maintained for at least a year. ${ }^{7}$ The NHLBI recommends that weight loss programs strive for an initial weight loss of approximately $10 \% .{ }^{10}$ Therefore, in addition to the traditional weight maintenance measures, we will report on the percentage of participants who have maintained a weight loss of at least $5 \%$ and at least $10 \%$, as well as the percentage who remain below their starting weight.

During the past $15 \mathrm{y}$ Weight Watchers, the commercial program upon which this report is based, has conducted a series of telephone surveys of its lifetime members to determine how well their weight losses were maintained. Lifetime members are those Weight Watchers participants who successfully complete both the weight-loss and 6-week maintenance programs. Successful completion of the program is defined as achieving and maintaining (within $2 \mathrm{lb}$ ) a weight goal determined by the member and within a body mass index of 20-25 (or otherwise set by the member's physician). Results of a survey conducted in 1993 have been published. ${ }^{11}$

This 1993 survey, like many others involving large, geographically dispersed populations, assessed current weight via self-report. While many researchers have reported a high correlation $(>0.90)$ between self-report and measured weight, ${ }^{12}$ the appropriateness of using self-reported weight has been questioned because of systematic underreporting among some sub-sets of the population, including women, ${ }^{13}$ overweight individuals, ${ }^{14}$ and those over the age of $45 .^{15}$ DelPrete et $\mathrm{al}^{16}$ compared self-reported and measured weights in 82 adults $1-3 \mathrm{y}$ following participation in a community weight-loss program. The average self-reported weight was $2.7 \mathrm{~kg}$ less than measured weight. Similar results were obtained by Tell et $a{ }^{17}{ }^{17}$ who concluded that, unless a correction is made to increase the level of accuracy, selfreported weights should not be used to evaluate long-term maintenance of weight losses.

Therefore, in addition to surveying a national sample of Weight Watchers lifetime members, we recruited an oversample of lifetime members who were chosen using the same procedures used with the national sample. Actual weights were obtained on the oversample so that a correction factor could be developed and applied to the self-reported weights obtained from the national sample.

\section{Method}

\section{Procedure}

All participants had formerly been Weight Watchers members and reached goal weight while in the program. The Weight Watchers program includes a food plan, an activity plan, and a behavior modification plan focused primarily on cognitive restructuring. The food plan is a nutritionally balanced, moderate deficit diet designed to produce a weight loss of up to $0.9 \mathrm{~kg}$ per week. The activity plan involves the recommendation to accumulate $30 \mathrm{~min}$ of physical activity on most (preferably all) days of the week. Weekly group meetings, led by successful program graduates who act as role models, provide written educational materials, a weekly weigh-in, and social support.

Goals weights are determined by the individual member and must be at least $5 \mathrm{lb}$ less than the member's joining weight. Members are encouraged to select a weight goal within the BMI range of 20-25. Because lifetime status comes with free services and most members have a substantial amount to lose, the vast majority choose a weight goal equivalent to a BMI of 25. In addition, Weight Watchers confers lifetime member eligibility to members who provide a weight goal from a qualified health professional who has stated that the prescribed weight (even if above a BMI of 25) is deemed healthy based on an individual assessment of the member.

To locate lifetime members, a zip code analysis was conducted to identify and stratify primary areas in the country that were representative of different Weight Watchers membership enrollment sizes. Fifteen primary areas were given specific backup areas, in case a reliable market research facility was unavailable in the immediate vicinity of a primary area. All interviewing was conducted in either the primary or backup areas.

The first sample of participants (the national sample) was selected from national Weight Watchers lifetime members covering the years 1992-1996. Of the database's 189780 participants, over 61000 were ineligible due to incorrect 
telephone or zip code numbers. Quotas were set for each membership year and the telephone survey was administered to a subsample of 1002 randomly selected lifetime members.

In order to verify self-reported weights, a second sample (the oversample) was recruited at about the same time, following the same stratification procedure described above. Of the oversample participants called, 643 agreed to participate. Lifetime members in the national and oversamples were interviewed in exactly the same way, except respondents in the oversample were asked if they would be willing to participate in an additional survey to be conducted at a nearby facility. During oversample recruitment, respondents were not told that they would be weighed as part of the additional survey. Interviews were conducted over the telephone by an independent research firm. Those subjects who stated a willingness to participate in the additional survey were contacted by the local market research facility to schedule an appointment. An incentive of \$25 was offered to encourage participation in the additional survey. Respondents who attended the follow-up session but refused to be weighed were offered an additional \$25 in order to ensure the validity of the sample. Of the 259 participants in the additional survey, nine received the additional incentive and one refused to be weighed regardless of the incentive offered.

\section{Phone-based survey}

The survey interview was designed by Weight Watchers to assess long-term maintenance of weight loss and pertinent patient demographics. Goal weight (ie 'What was your initial goal weight as set by Weight Watchers?') and weight loss to achieve goal (ie 'How many pounds did you lose to reach that goal weight?') were assessed. Respondents were also asked to give their current weight (ie 'What is your present weight?'). Oversample participants who attended the additional survey session were weighed to the nearest $0.09 \mathrm{~kg}$ on a digital scale (Tanita Corporation, Skokie, IL). Participants were weighed with their clothes and shoes on.

\section{Statistical analyses}

SPSS 8.0 was used for statistical analyses. Categorical data are presented in percentage terms. Continuous data are presented as mean \pm standard deviation. The chi-square test was used to assess differences between categorical variables. ANOVA was used to assess differences between groups on continuous variables. Post-hoc analyses were conducted using Bonferroni comparisons. Pearson correlation coefficients were used to assess relationships between continuous variables. The relationship between demographic variables (ie age, gender, employment and marital status) and weight regain was assessed by the general linear model factorial procedure (ANCOVA) with two covariates (ie membership year and initial weight) entered into the model.

\section{Results}

Sample characteristics

National sample participants were overwhelmingly female (96\%), married (85\%) and employed (69\%). Most were in their 40 s and 50s and had family incomes over $\$ 40000$ per year. There were no differences between the national $(n=1002)$ and oversample $(n=259)$ participants in gender, age, martial status, income or employment (Table 1). Participants in the oversample who attended and were weighed at the weigh-in session $(n=258)$ reported higher weights than those $(n=191)$ who declined to participate $(67.1 \pm 9.8 \mathrm{vs}$ $64.9 \pm 8.4 \mathrm{~kg}$, respectively) and than those $(n=194)$ who agreed to participate but didn't attend the weigh-in session $(65.7 \pm 9.2 \mathrm{~kg} ; F=3.0, P=0.05)$. No differences were found in self-reported weight between oversample participants who attended the weigh-in and those in the national sample (although as a group the oversample weighed an average of $1.0 \mathrm{~kg}$ more than the national sample).

\section{Correction factors}

The self-reported and measured weights of the oversample are shown in Table 2 . In order to adjust for any bias in selfreported weights, two correction factors were compared.

Table 1 Demographic characteristics of national and over samples

\begin{tabular}{|c|c|c|}
\hline Variable & National $(n=1002)$ & Oversample $(\mathrm{n}=258)$ \\
\hline \multicolumn{3}{|l|}{ Gender } \\
\hline Male & $4.2 \%$ & $5.0 \%$ \\
\hline Female & $95.8 \%$ & $95.0 \%$ \\
\hline Self-reported weight in kg & $66.1 \pm 9.4$ & $67.1 \pm 9.8$ \\
\hline \multicolumn{3}{|l|}{ Age } \\
\hline Under 18 & $0.0 \%$ & $0.0 \%$ \\
\hline $18-24$ & $0.7 \%$ & $0.4 \%$ \\
\hline $25-29$ & $3.0 \%$ & $2.7 \%$ \\
\hline $30-34$ & $8.7 \%$ & $10.9 \%$ \\
\hline $35-44$ & $31.9 \%$ & $32.2 \%$ \\
\hline $45-54$ & $31.5 \%$ & $30.2 \%$ \\
\hline $55-64$ & $15.7 \%$ & $14.0 \%$ \\
\hline 65 and over & $8.6 \%$ & $9.7 \%$ \\
\hline \multicolumn{3}{|l|}{ Marital status } \\
\hline Single & $7.2 \%$ & $6.2 \%$ \\
\hline Married & $84.8 \%$ & $85.2 \%$ \\
\hline Separated or divorced & $4.2 \%$ & $5.1 \%$ \\
\hline Widowed & $3.9 \%$ & $3.5 \%$ \\
\hline \multicolumn{3}{|l|}{ Income } \\
\hline Under $\$ 20000$ & $4.6 \%$ & $2.0 \%$ \\
\hline$\$ 20000$ to under $\$ 25000$ & $4.1 \%$ & $2.0 \%$ \\
\hline$\$ 25000$ to under $\$ 30000$ & $6.9 \%$ & $3.4 \%$ \\
\hline$\$ 30000$ to under $\$ 35000$ & $6.2 \%$ & $8.4 \%$ \\
\hline$\$ 35000$ to under $\$ 40000$ & $8.6 \%$ & $7.4 \%$ \\
\hline$\$ 40000$ to under $\$ 50000$ & $15.2 \%$ & $14.8 \%$ \\
\hline$\$ 50000$ to under $\$ 75000$ & $26.5 \%$ & $31.5 \%$ \\
\hline$\$ 75000$ and over & $27.8 \%$ & $30.5 \%$ \\
\hline Employed (outside home) & $69.0 \%$ & $67.1 \%$ \\
\hline Full-time & $77.3 \%$ & $74.6 \%$ \\
\hline Part-time & $22.7 \%$ & $25.4 \%$ \\
\hline
\end{tabular}

Note: categorical data are percentage frequency. Continuous data are mean \pm s.d. No significant differences were found across rows. 
Table 2 Correction factors derived from oversample participants $(n=258)$

\begin{tabular}{lccc}
\hline Year $(\mathrm{n})$ & $\begin{array}{c}\text { Self-reported } \\
\text { weight }\end{array}$ & $\begin{array}{c}\text { Measured } \\
\text { weight }\end{array}$ & $\begin{array}{c}\text { Discrepancy between } \\
\text { reported }\end{array}$ \\
\hline $1992(50)$ & $70.2 \pm 11.5$ & $72.3 \pm 12.2$ & 0.03 \\
$1993(50)$ & $67.9 \pm 10.7$ & $70.7 \pm 11.4$ & 0.04 \\
$1994(56)$ & $67.1 \pm 10.5$ & $69.0 \pm 11.4$ & 0.03 \\
$1995(66)$ & $64.5 \pm 7.4$ & $66.4 \pm 8.1$ & 0.03 \\
$1996(36)$ & $65.8 \pm 7.2$ & $66.8 \pm 7.8$ & 0.02 \\
Average & $67.0 \pm 9.8$ & $69.0 \pm 10.5$ & 0.03 \\
\hline
\end{tabular}

Note: measured weights were obtained at various times of the day in street clothes and shoes.

Using the oversample $(n=258)$, the first correction factor was computed by calculating the average percentage discrepancy between measured and self-reported weight (ie (measured weight - self-reported weight)/measured weight). This was multiplied by self-reported weight and then added to self-reported weight to obtain corrected weights. The average degree of underreporting in the oversample was $2.0 \pm 3.6 \mathrm{~kg}$ or $2.7 \pm 5 \%$.

The second correction factor was computed by calculating the average degree of underreporting that occurred within each year (ie 0.031 for 1992, 0.042 for 1993, 0.027 for 1994, 0.029 for 1995 and 0.018 for 1996), multiplying the results by self-reported weight, and adding the correction to selfreported weight (eg corrected weight for 1992: (self-reported weight $\times 0.031)+$ self-reported weight). The degree of discrepancy between self-reported and measured weights differed little from year to year (Table 2). Corrected weights in analyses reported below are based on yearly correction factors (ie the second correction method).

\section{Weight maintenance}

Weight maintenance was examined from several perspectives. These included: (1) the amount (in $\mathrm{kg}$ ) and percentage of weight loss regained; (2) percentage of participants who remained within $5 \mathrm{lbs}$ of goal weight; (3) percentage of participants who maintained a weight loss of at least 5\%, and the percentage who maintained a weight loss of at least $10 \%$, of initial body weight; and (4) percentage of participants who were still below their initial weight. Finally, we assessed the percentage of participants whose current weight was below their goal weight (ie who had lost and kept off additional weight since reaching goal weight).

Overall, participants reported losing $12.2 \pm 8.4 \mathrm{~kg}$ to reach their goal weight. Of this, participants regained an average of $5.8 \mathrm{~kg}$ ( $56.4 \%$ of initial weight loss). Less than one-third $(28.3 \%)$ of participants had remained within $5 \mathrm{lb}$ of goal weight since becoming lifetime members; $56.8 \%$ maintained $5 \%$ or greater weight loss and $79.6 \%$ remained below the weight they were before beginning Weight Watchers (Table 4). Amount of regain was less when uncorrected weights were used (Table 3). Over time, amount of regain increased, with 1992 members regaining $7.4 \mathrm{~kg}$ and 1996 members regaining $2.9 \mathrm{~kg}(F=23.1, P<0.001$; see Table 4$)$.

Simultaneous regression analysis predicting weight regain with age, employment status, gender and marital status entered into the equation (while controlling for membership year and initial weight) was nonsignificant.

\section{Supplemental analyses}

Degree of body weight underestimation was significantly correlated with actual $(0.37, P<0.001)$ but not self-reported weight; thus heavier participants underestimated to a greater

Table 3 Uncorrected regain among national sample participants $(n=1002)$

\begin{tabular}{|c|c|c|c|c|c|c|}
\hline & $\begin{array}{c}1992 \\
\text { Mean s.d. }\end{array}$ & $\begin{array}{c}1993 \\
\text { Mean s.d. }\end{array}$ & $\begin{array}{c}1994 \\
\text { Mean s.d. }\end{array}$ & $\begin{array}{c}1995 \\
\text { Mean s.d. }\end{array}$ & $\begin{array}{c}1996 \\
\text { Mean s.d. }\end{array}$ & $\begin{array}{c}\text { Overall } \\
\text { Mean s.d. }\end{array}$ \\
\hline $\mathrm{kg}$ regain & 5.45 .6 & 5.67 .9 & 4.25 .4 & 3.75 .2 & 1.75 .0 & 3.95 .8 \\
\hline Percentage weight loss regained & 53.357 .5 & 46.25 .0 & 39.252 .7 & 32.352 .3 & 18.040 .6 & 35.252 .3 \\
\hline Percentage within $5 \mathrm{lb}$ of goal & 37.9 & 40.3 & 46.0 & 47.2 & 66.5 & 48.9 \\
\hline Percentage maintained $\geq 5 \%$ loss & 61.4 & 58.7 & 71.8 & 76.0 & 83.2 & 72.4 \\
\hline Percentage maintained $\geq 10 \%$ loss & 30.0 & 37.6 & 45.5 & 48.4 & 59.0 & 46.4 \\
\hline Percentage below initial weight & 84.9 & 83.1 & 88.3 & 90.6 & 94.5 & 89.3 \\
\hline Percentage goal weight & 11.5 & 13.3 & 18.4 & 18.7 & 29.9 & 19.2 \\
\hline
\end{tabular}

Table 4 Corrected regain among national sample participants $(n=1002)$

\begin{tabular}{|c|c|c|c|c|c|c|}
\hline & $\begin{array}{c}1992 \\
\text { Mean s.d. }\end{array}$ & $\begin{array}{c}1993 \\
\text { Mean s.d. }\end{array}$ & $\begin{array}{c}1994 \\
\text { Mean s.d. }\end{array}$ & $\begin{array}{c}1995 \\
\text { Mean s.d. }\end{array}$ & $\begin{array}{c}1996 \\
\text { Mean s.d. }\end{array}$ & $\begin{array}{c}\text { Overall } \\
\text { Mean s.d. }\end{array}$ \\
\hline $\mathrm{kg}$ regain & 7.45 .8 & 8.48 .3 & 6.05 .6 & 5.75 .4 & 2.95 .1 & 5.76 .1 \\
\hline Percentage weight loss regained & 76.561 .2 & 77.960 .1 & 59.857 .9 & 53.754 .8 & 31.544 .3 & 56.457 .1 \\
\hline Percentage within $5 \mathrm{lb}$ of goal & 19.4 & 14.7 & 27.0 & 25.9 & 47.6 & 28.3 \\
\hline Percentage maintained $\geq 5 \%$ loss & 42.6 & 46.0 & 54.3 & 60.1 & 69.6 & 56.8 \\
\hline Percentage maintained $\geq 10 \%$ loss & 18.8 & 30.2 & 32.4 & 35.0 & 51.6 & 35.4 \\
\hline Percentage below initial weight & 70.3 & 60.2 & 80.0 & 82.7 & 92.5 & 79.6 \\
\hline Percentage below goal weight & 3.9 & 4.7 & 11.1 & 11.5 & 17.8 & 10.9 \\
\hline
\end{tabular}


degree than lighter participants. Underestimation was also greater among those who regained the most based on corrected regain $(r=0.57, P<0.001)$ but was not correlated with self-reported weight regain. Furthermore, based on corrected data, oversample participants who attended the weigh-in session regained significantly more weight than those who agreed to participate but who failed to show up for the weigh-in session $(6.3 \pm 6.1$ and $4.9 \pm 5.1 \mathrm{~kg}$, respectively, $t=4.1, \quad P<0.02)$. No differences in weight regain were found between those who attended the weigh-in session and those who refused to participate.

The initial weight (before achieving goal) of lifetime members was not reported in this survey, but could be inferred based on amount of the self-reported weight losses and goal weights. The amount of weight loss remained the same across years and goal weights increased across time; thus, it appears that initial weights increased across time (Table 5).

\section{Discussion}

The disappointing data on long-term maintenance of weight losses has been based on the minority of overweight dieters who participate in controlled research studies in clinical settings. The present study is the first to examine longterm maintenance of weight loss among participants who had reached goal weight in a commercial weight loss program. Thus this study provides information about weight loss maintenance in a group of overweight individuals who are more representative of those who participate in organized programs to control their weight. Furthermore, weight maintenance was assessed in a large sample drawn from many regions of the United States, and self-reported weight information was corrected for possible reporting bias.

Using corrected data, the results of this study suggest that in the near term ( $1 \mathrm{y}$ following achievement of goal weight), the level of weight regain shown by the lifetime members was comparable to that found in clinical studies (about onethird of lost weight was regained after $1 \mathrm{y}$ ). The level of weight regain increased across the $5 \mathrm{y}$ of the study, but the percentage of weight regained at $5 \mathrm{y}(76.5 \%)$ was better than that reported in research using clinical populations. ${ }^{2}$ Other indices of long-term weight maintenance also suggest that the lifetime members maintained their weight losses better than the results of clinical studies would lead one to expect. The percentage of participants who were still within $5 \mathrm{lb}$
$(2.27 \mathrm{~kg})$ of goal weight after $5 \mathrm{y}$ was $19.4 \%$. Since the Institute of Medicine ${ }^{7}$ suggested that a $5 \%$ weight loss that is maintained will have significant health benefits, we examined this outcome as well; $42.6 \%$ of Lifetime Members had maintained a weight loss of $5 \%$ or more after $5 \mathrm{y}$. Finally, a substantial majority (70\%) of participants were still below their starting weight $5 \mathrm{y}$ later. In the absence of a weight-loss intervention, overweight individuals would be expected to gain weight over a $5 \mathrm{y}$ period. ${ }^{18}$ This fact makes even a minor sustained weight loss (in most participants) a noteworthy achievement.

The present study provides data on long-term weight maintenance of participants in a particular commercial weight loss program, a population that has been insufficiently studied in the past. ${ }^{7}$ Nonetheless, the data collected are not directly comparable to data from clinical studies because the participants in this study had all reached goal weight. Although the total number of participants who have attained Lifetime Member status in Weight Watchers is sizable (about 1.8 million), they represent only a fraction of the number of individuals who have enrolled in the Weight Watchers program. Data on long-term outcomes in clinical populations, on the other hand, are based on a majority of those who initially enrolled in a program. Thus if only the most successful participants in clinical programs were followed for $5 \mathrm{y}$, they would probably achieve weight maintenance results superior to those reported for participants overall. Conversely, it cannot be assumed that the weight maintenance results achieved by Weight Watchers' members who (unlike lifetime members) progressed only part way to their goal weight would be comparable to those reported here.

A second reason that the data in this study are not directly comparable to those reported in clinical studies is that information on goal weights and amount lost to reach goal weight was based on self-report. The weight losses to achieve goal weight were quite consistent across years, as were the reported percentage reductions in weight to reach goal weight. Lending further credence to the respondents' selfreports is the fact that, extrapolating from the self-report data, the starting weights of respondents gradually increased across the $5 \mathrm{y}$ (from 60.8 to $63.5 \mathrm{~kg}$ ), which is consistent with the increase in body mass in the general population in recent years. ${ }^{19}$ In sum, although participants in this study did in fact reach goal weight during their participation in Weight Watchers, the accuracy of data on the absolute amount of weight lost to reach goal weight is unknown.

Table 5 Goal weights and weight losses by year of entry among national sample $(n=1002)$

\begin{tabular}{|c|c|c|c|c|c|c|}
\hline & 1992 & 1993 & 1994 & 1995 & 1996 & Overall \\
\hline Goal weight (kg) & $60.4 \pm 6.1^{\mathrm{ad}}$ & $60.6 \pm 6.2^{\mathrm{ab}}$ & $61.9 \pm 7.0^{\mathrm{abcd}}$ & $62.9 \pm 6.9^{\mathrm{acd}}$ & $63.6 \pm 7.2^{\mathrm{d}}$ & $63.5 \pm 7.2$ \\
\hline Weight loss to goal weight $(\mathrm{kg})$ & $10.9 \pm 6.3^{\mathrm{a}}$ & $12.0 \pm 7.5^{\mathrm{a}}$ & $12.6 \pm 9.7^{\mathrm{a}}$ & $12.1 \pm 8.0^{\mathrm{a}}$ & $12.1 \pm 7.7^{\mathrm{a}}$ & $12.1 \pm 8.1$ \\
\hline Percentage reduction to goal weight & $14.7 \pm 6.1^{\mathrm{a}}$ & $15.7 \pm 7.2^{\mathrm{a}}$ & $15.7 \pm 8.4^{\mathrm{a}}$ & $15.4 \pm 7.2^{\mathrm{a}}$ & $15.2 \pm 7.0^{\mathrm{a}}$ & $15.4 \pm 7.3$ \\
\hline
\end{tabular}

Note: unshared superscripts differ significantly in Bonferroni post-hoc comparisons $(P<0.01)$. 
A third difference between the present data and that from clinical studies is that information on height was not collected in the current study. Although there is no reason to believe that differences in participants' heights would have any systematic influence on the results reported here, the absence of height data means that relative weights of the participants could not be characterized.

A final difference between the present results and those reported in clinical studies is that most participants in clinical studies are substantially more overweight than those studied here. In our study the correlations between weight regain (percentage of lost weight that was regained) and starting weight were significant though modest (range $0.16-0.23$ ) for each of the $5 \mathrm{y}$ of follow-up. Thus it is possible that more overweight individuals would have regained more weight than those studied here.

A unique aspect of this study was its use of a correction factor based on the measured weights of an oversample chosen in the same way as the national sample. The correction factor must be interpreted with the following points in mind. First, oversample participants who attended the weigh-in session were significantly heavier than those who did not, and weighed on average $1 \mathrm{~kg}$ more than the national sample. Since there was a significant correlation (0.37) between body weight underestimation and actual weight (in the oversample), this means that the correction factor derived from the oversample probably represented an overcorrection when applied to the national sample. Thus the corrected results reported here may be too conservativethat is, they may understate the actual level of achieved weight loss maintenance.

Second, self-reported weights were presumably based on participants weighing themselves at home. These measurements probably differed from those taken during the oversample assessment session. One reason for this is that most weight conscious individuals weigh themselves in the morning with little clothing on. Oversample participants were all weighed during the day wearing indoor clothing and shoes. The oversample procedure would result in spuriously higher weights and therefore to an inflated difference between selfreported and measured weights. These measurement differences would again lead to overly conservative correction factors that would make the weight maintenance results appear worse than they really were. In sum, if oversample participants had based their self-reported weights on weights measured under the same conditions as used to actually measure the weights of oversample participants, there may have been a smaller discrepancy between self-reported and measured weights.

The primary implication of this study is that the weight maintenance prognosis for individuals who reach goal weight in at least one commercial weight loss program may be better than that suggested by the results of controlled research. A recent multi-site trial of Orlistat ${ }^{20}$ used a methodology similar to that employed here. Only patients who were successful (minimum of $8 \%$ weight loss) in an initial dietary restriction phase of the trial were randomized to receive placebo or one of three doses of Orlistat. While weight loss medications are often viewed as producing superior weight loss maintenance as long as the drug is being administered, the rate of weight regain (on the optimum Orlistat dosage) in this study was comparable to that found in the present study.

Not surprisingly, before losing weight most of the lifetime members studied here were in the overweight range (BMI of 25 -30) rather than in the obese range (BMI > 30). However, since even modest overweight confers health risks, ${ }^{20}$ and since there are far more moderately than severely overweight individuals, the level of weight loss maintenance demonstrated by the lifetime members could have important public health implications if they could be achieved on a more widespread basis.

The discouraging conclusion from most clinical studies is that almost everyone returns to, or surpasses, their starting weight within $5 \mathrm{y}$ following treatment. If this conclusion is overly pessimistic when applied to overweight individuals considering participation in a nonclinical program, it could discourage them from seeking professional assistance that could reduce their risk of medical conditions associated with obesity. As noted by the National Task Force on Prevention and Treatment of Obesity, ${ }^{22}$ 'consideration should be given to the fact that most of the data concerning weight loss and regain are derived from studies of patients who sought medical help because of particular difficulties with weight. These individuals may represent a specific population that is refractory to weight loss and does not mirror the general population accurately' (pp 576-577). The fact that after $5 \mathrm{y}$ the great majority of lifetime members reported weighing less than they did before joining Weight Watchers suggests that many of them may have reduced their risk of obesityrelated comorbid conditions for at least several years. Future research should actually examine the progression of health risk factors over time among those who reach their goal weights, and also study long-term outcomes among those who lose a meaningful amount of weight in a commercial program but do not reach goal weight.

In addition to this and a previous study ${ }^{11}$ on long-term outcome, a randomized, controlled study of the short-term effects of the Weight Watchers program has been published. ${ }^{21}$ Furthermore, a large-scale, prospective clinical trial of the Weight Watchers program is currently underway. ${ }^{24}$ Compared with existing studies conducted in clinical settings, this increased emphasis on empirical evaluations of commercial weight loss programs will provide a more balanced picture of the risk and benefits of weight loss in overweight individuals.

\section{References}

1 National Task Force on the Prevention and Treatment of Obesity. Long-term pharmacotherapy in the management of obesity. JAMA 1996; 276: $1907-1915$. 
2 Wadden TA, Sarwer DB. Behavioral treatment of obesity: new approaches to an old disorder. In: Goldstein D (ed). The management of eating disorders. Humana Press: Totowa, NJ; 1999.

$3 \mathrm{NIH}$ Technology Assessment Conference Panel. Methods for voluntary weight loss and control. Ann Intern Med. 1993; 119: $764-770$.

4 Garner DM, Wooley SC. Confronting the failure of behavioral and dietary treatments for obesity. Clin Psychol Rev 1991; 11: $729-780$.

5 Brownell KD. Whether obesity should be treated. Health Psychol 1993; 12: 339-341.

6 Fitzgibbon ML, Stolley MR, Kirschenbaum DS. Differential characteristics of obese individuals who do or do not seek treatment. Health Psychol. 1993; 12: 342-345.

7 Committee to Develop Criteria for Evaluating the Outcomes of Approaches to Prevent and Treat Obesity. Weighing the options: criteria for evaluating weight-management programs. Obes Res 1995; 3: 591-604. (Reprinted from Weighing the options: criteria for evaluating weight-management programs, by the National Academy of Sciences, National Academy Press: Washington, DC; 1994).

8 Hensrud DD, Weinsier RL, Darnell BE, Hunter GR. Relationship of co-morbidities of obesity to weight loss and four-year weight maintenance/rebound. Obes Res 1995; 3: 217s-222s.

9 Blackburn GL. Effect of degree of weight loss on health benefits. Obes Res 1995; 3: 211s-216s.

$10 \mathrm{NIH} / \mathrm{NHLBI}$ clinical guidelines on the identification, evaluation, and treatment of overweight and obesity in adults: the evidence report. Obes Res 1998; 6: 51S-210S.

11 Christakis G, Miller-Kovach K. Maintenance of weight goal among Weight Watchers Lifetime Members. Nutr Today 1996; 31: $29-31$.

12 Rimm EB, Stampfer MJ, Colditz GA, Chute CG, Litin LB, Willett WC. Validity of self-reported waist and hip circumferences in men and women. Epidemiology 1990; 1: 466-473.
13 Palta M, Prineas RJ, Berman R, Hannan P. Comparison of selfreported height and weight with controlled height and weight in women and men. Am J Epidemiol 1982; 115: 223-230.

14 Schlichting P, Hoilund-Carlsen PF, Quaade F. Comparison of selfreported height and weight with controlled height and weight in men and women. Int J Obes 1981; 5: 67-76.

15 Rowland ML. Self-reported weight and height. Am J Clin Nutr. 1990; 52: 1125 - 1133

16 Delprete LR, Caldwell M, English C, Banspach SW, Lefebvre C. Selfreported and measured weights and heights in community-based weight loss programs. J Am Diet Assoc 1992; 92: 1483-1486.

17 Tell GS, Jeffrey RW, Kramer FM, Snell MK. Can self-reported body weight be used to evaluate long-term follow-up of a weight-loss program? Am J Dietet Assoc 1987; 87: 1198-2101.

18 Brownell KD, Kramer M. Behavioral management of obesity. Med Clin N A 1989; 73: $185-201$

19 Kuczmarski RJ, Flegal KM, Campbell SM, Johnson CL. Increasing prevalence of overweight among US adults. JAMA 1994; 272: 205-211.

20 Calle EC, Thun M, Petrelli JM, Rodriguez C, Heath CW. Bodymass index and mortality in a prospective cohort. New Engl J Med 1999; 341: $1097-2002$.

21 Hill JO, Hauptman J, Anderson JW, Fujioka K, O'Neil PM, Smith $\mathrm{DK}$, Zavoral JH, Aronne LJ. Orlistat, a lipase inhibitor, for weight maintenance after conventional dieting: a 1-y study. Am J Clin Nutr 1999; 69: 1108-1116.

22 National Task Force on the Prevention and Treatment of Obesity Towards Prevention of obesity: research directions. Obes Res 1994; 2: $571-583$.

23 Lowe MR, Miller-Kovach K, Frye N, Phelan S. An initial evaluation of a commercial weight loss program: short-term effects on weight, eating behavior, and mood. Obes Res. 1999; 7: 51-59.

24 Heshka S, Greenway F, Miller-Kovach K, Pi-Sunyer FX. Structured commercial weight loss program improves homocysteine levels compared to self-help weight loss. FASEB J 1999; 13: A269. 